\title{
A study of assessing knowledge, attitude and practice of pharmacovigilance among medical students of a South Indian teaching hospital
}

\author{
Kulkarni Dhananjay $^{1}$, Esanakula Himasri ${ }^{2}$
}

${ }^{1}$ Department of Pharmacology, Mahavir Institute of Medical Sciences, Vikarabad, Telangana 501101, India

${ }^{2}$ Konaseema Institute of Medical Sciences and Research Foundation (KIMS and RF), Amalapuram, Andhra Pradesh 533201, India

Received: 29 November 2016 Accepted: 03 December 2016

\section{*Correspondence to:}

Dr. Kulkarni Dhananjay, Email: ksdhanu@rediffmail.com

Copyright: (C) the author(s), publisher and licensee Medip Academy. This is an openaccess article distributed under the terms of the Creative Commons Attribution NonCommercial License, which permits unrestricted noncommercial use, distribution, and reproduction in any medium, provided the original work is properly cited.

\begin{abstract}
Background: Pharmacovigilance is the science relating to detection, assessment, understanding and prevention of adverse drug reaction. The purpose is to improve patient safety in relation to use of medicines. It is estimated that only 6-10\% of adverse drug reactions (ADRs) are reported worldwide. The underreporting of ADR is due to lack of adequate knowledge, attitude and practice among healthcare professionals towards ADR reporting. Health care professional like physicians, pharmacist and nurses have immense responsibility in reporting ADR. Therefore, the objective of this study was to evaluate the knowledge, attitude and practices (KAP) of undergraduate medical students towards pharmacovigilance.

Methods: A cross-sectional KAP based questionnaires study was carried out in 100 undergraduate students of Konaseema Institute of Medical Sciences, Amalapuram. The response of KAP questionnaires were analyzed in percentage and tabular form.

Results: Nearly $87 \%$ participants heard about pharmacovigilance, but only $65 \%$ know its need or purpose. $88 \%$ people feel that ADR reporting may improve patient safety. Less than half of the students know about Institutional ADR centre. $81 \%$ students have seen ADR but only $31 \%$ knew about ADR reporting form and surprisingly only $20 \%$ have reported ADR. More than $80 \%$ feels reporting ADR will increase patient safety.

Conclusions: Participants have good knowledge about Pharmacovigilance but lacks in attitude and practice towards reporting ADR. Greater awareness of pharmacovigilance and incorporation of it in medical curriculum will further strengthen pharmacovigilance activity.
\end{abstract}

Keywords: Adverse drug reaction (ADR), Drug safety, Knowledge Attitude practice (KAP), Pharmacovigilance

\section{INTRODUCTION}

Pharmacovigilance (PV or PhV), also known as drug safety, is the pharmacological science and activities relating to the collection, detection, assessment, monitoring, and prevention of adverse effects with pharmaceutical products. ${ }^{1}$ The dark history in 1961 by use of the drug thalidomide in pregnancy causing the birth of thousands of congenitally deformed babies led to the initiation of first organized international efforts to address drug safety issues. Further, this episode introduced the adoption of tougher testing, rigorous drug approval and monitoring systems like United States Food and Drug Administration (FDA). ${ }^{2}$ The expansion of scientific knowledge in drug safety is attributable to greater awareness and academic interest in this field. In many medical institutions, particularly in the developed countries, adverse drug reaction (ADR) monitoring is recognized as an essential quality assurance activity. ${ }^{3}$ Greater integration of pharmacovigilance into clinical 
practice is still needed. Drug safety should feature in the medical and pharmacy curriculum.

Self-medication and the lack of regulatory control measures over the sale of drugs further increase the risk of adverse reactions. The number of drugs in each prescription is highest in developing countries. ${ }^{4}$ Factors such as illiteracy, concomitant use of traditional medicines, and availability of impure and irrational pharmaceutical preparations contribute further to the risk. It is estimated that only $6-10 \%$ of ADRs are reported worldwide. ${ }^{5}$ The Pharmacovigilance Programme of India (PvPI) was launched under the Ministry of Health and Family Welfare in July 2010 to safeguard the health of the Indian population by ensuring the safety of the marketed drugs. ${ }^{6}$ Uppsala Monitoring Centre (UMC), located in Uppsala, Sweden, is the field name for the World Health Organization (WHO) Collaborating Centre for International Drug Monitoring. UMC works by collecting, assessing and communicating information from member country's national pharmacovigilance centers in regard to the benefits, harm, effectiveness and risks of drugs. ${ }^{7}$ The main focus and source of data in pharmacovigilance are reports of ICSRs (individual case safety reports) from healthcare providers and patients in member countries of the WHO Programme. A WHO global individual case safety report database (Vigi Base) is maintained and developed on behalf of the WHO by UMC. ${ }^{8}$

The underreporting of ADR may be due to lack of adequate knowledge, attitude and practice among healthcare professionals towards ADR reporting. ${ }^{9}$ Health professionals are more likely to identify and report important ADRs if they have confidence in their ability to diagnose, manage and prevent such reactions. Pharmacovigilance Programme of India (PvPi) plays a vital role by encouraging the activities of pharmacovigilance in the field of medicine, pharmacy and nursing. The Adverse Drug reaction monitoring center (AMC) in Konaseema Institute of Medical Sciences and Research Foundation was also established in 2016 under PvPI. Therefore on this background, the present questionnaire based study was conducted to assess the knowledge, attitude and practice of spontaneous ADR reporting among future budding doctors; medical students.

\section{METHODS}

A cross sectional questionnaire (KAP) based study was conducted among 100 undergraduate medical students after due approval of Institutional Ethical Committee. Willingness to participate and completing the questionnaire was taken as consent for the study.

\section{Type of study}

It was a cross-sectional, KAP questionnaire based study. About 100 undergraduate medical students were included in this study. A questionnaire consisting of 14 questions was prepared with reference from previous studies on pharmacovigilance with minor modifications. ${ }^{10-14}$

After explaining the study purpose, questionnaire was distributed to all the participants with 30 minutes time allotted to fill it. The KAP questionnaire was analyzed question wise and their percentage value was calculated. The knowledge based questions assessed, knowledge regarding various aspects of pharmacovigilance such as a location of local and national ADR monitoring centers, purpose, type of ADRs to be reported, who can report and how ADR reporting done. The attitude based-questions assessed the view of the participants regarding the impact of ADR, current system of Pharmacovigilance, obligation towards ADR reporting. The practice based-questions determined practice concerning reading articles, and reporting $\mathrm{ADR}$.

\section{RESULTS}

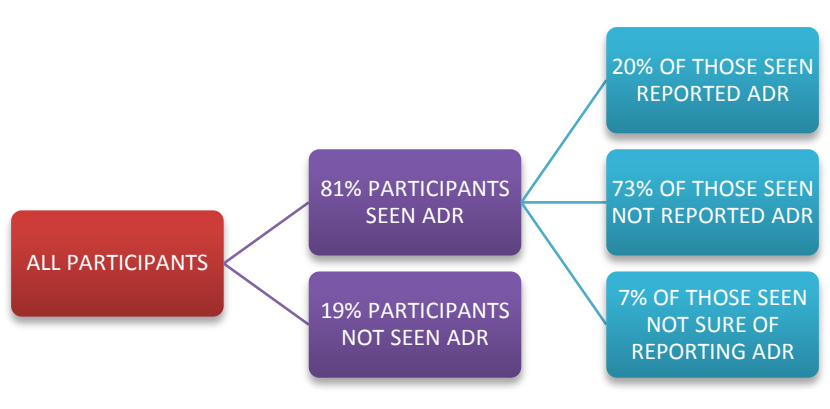

Figure 1: Attitude and practice of participants towards ADR reporting.

Figure 1 shows attitude towards reporting ADR. Out of $81 \%$ of those seen ADR, only $20 \%$ of them reported it.

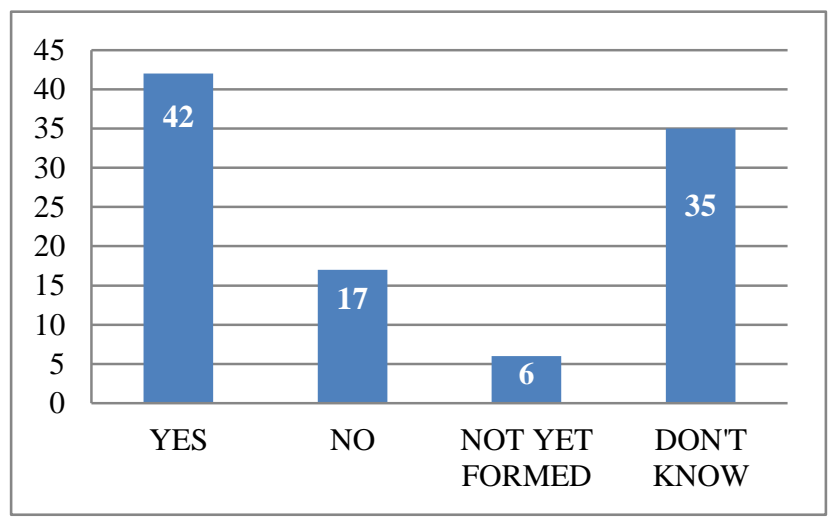

Figure 2: Knowledge of Institutional ADR monitoring centre.

Figure 2 shows only $42 \%$ participants know about institutional ADR centre. 
Figure 3 shows only $45 \%$ of the participants feels reporting $\mathrm{ARD}$ is professional obligation. However majority of the participants $(80 \%)$ felt need of pharmacovigilance to be taught in great detail to health care professional.
Out of all the participants, nearly $87 \%$ heard about pharmacovigilance, but only $65 \%$ know its need or purpose. The results are summarized as shown in Table 1.

Table 1: KAP questionnaire based study results.

\begin{tabular}{|lllll|}
\hline Sr. no & Question & $\begin{array}{l}\text { Correct/positive } \\
\text { Response (\%) }\end{array}$ & $\begin{array}{l}\text { Incorrect } \\
\text { response (\%) }\end{array}$ & $\begin{array}{l}\text { Not } \\
\text { responded } \\
\text { Nil }\end{array}$ \\
\hline 1. & Science of pharmacovigilance deals with & 87 & 13 & Nil \\
\hline 2. & Need and purpose of pharmacovigilance & 65 & 35 & 2 \\
\hline 3. & Name the regulatory body of ADR in India & 51 & 47 & 3 \\
\hline 4. & Where the International ADR monitoring centre is located? & 50 & 47 & 2 \\
\hline 5. & $\begin{array}{l}\text { Is there any Pharmacovigilance committee/ADR centre in } \\
\text { your institution? }\end{array}$ & 42 & 56 & 1 \\
\hline 6. & $\begin{array}{l}\text { Health care professionals responsible for reporting ADR } \\
\text { are }\end{array}$ & 47 & 52 & 8 \\
\hline 7. & $\begin{array}{l}\text { Do you think reporting an ADR is professional obligation } \\
\text { for Doctors? }\end{array}$ & 45 & 47 & 2 \\
\hline 8. & $\begin{array}{l}\text { Should pharmacovigilance be taught in detail to health care } \\
\text { professionals? }\end{array}$ & 80 & 18 & 76 \\
\hline 9. & Did you read any case report or article on ADR? & 6 & 18 & Nil \\
\hline 10. & Did you see an ADR reporting form? & 31 & 69 & Nil \\
\hline 11. & Have you ever seen ADR during clinical postings? & 81 & 19 & 7 \\
\hline 12. & If yes, have you ever reported ADR? & 20 & 73 & 9 \\
\hline 13. & Do you think reporting ADR will increase patient safety? & 88 & 3 & 11 \\
\hline 14. & $\begin{array}{l}\text { Name of "WHO online data base" available for reporting } \\
\text { ADR? }\end{array}$ & 11 & 78 & \\
\hline
\end{tabular}

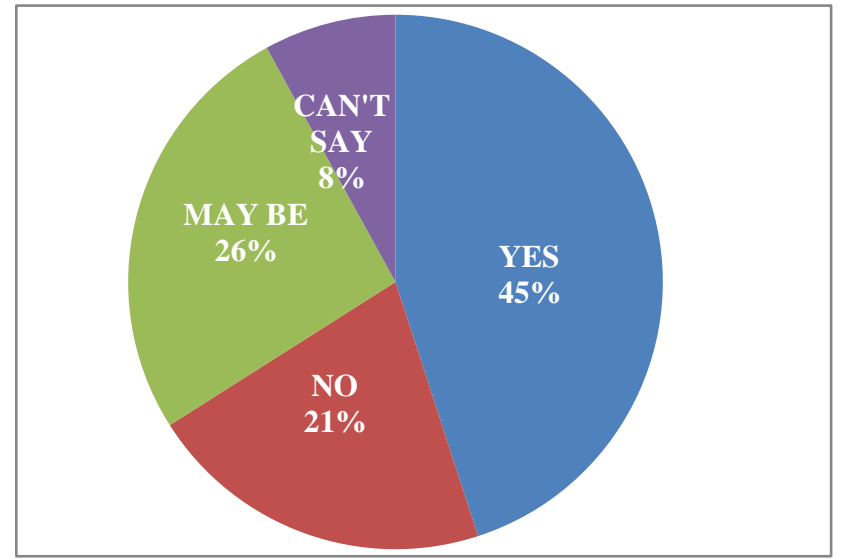

Figure 3: Is ADR reporting professional obligation for doctors?

\section{DISCUSSION}

The present study is a questionnaire-based study to assess the knowledge, attitude and practice of pharmacovigilance towards ADR reporting among doctors in a tertiary care teaching hospital. A spontaneous reporting system of ADRs is fundamental to drug safety surveillance but under-reporting is a well recognized issue. Numerous studies are done to assess the KAP of health care professionals towards pharmacovigilance, but a very few studies have been done among the undergraduate or postgraduate doctors to evaluate their knowledge. ${ }^{10,15,16}$ This study is one of the few studies done among 100 undergraduate medical students regarding KAP of pharmacovigilance. In our study, nearly $87 \%$ participants heard about pharmacovigilance, but only $65 \%$ know its need or purpose. Similar study in undergraduate medical students by Meher, et al recently reported that $33 \%$ of final, $41 \%$ of prefinal and $22 \%$ of second year students know the definition of pharmacovigilance. ${ }^{17}$ In Parthiban et al study it was concluded that $81 \%$ were aware of the term Pharmacovigilance, but among the participants who were aware, only $53 \%$ had a better knowledge about Pharmacovigilance and ADR reporting. ${ }^{18}$

In the present study, almost only half of the participants knew that Indian Pharmacopeia commission (IPC) Ghaziabad is the nodal body of pharmacovigilance in India (51\%) and UMC, Sweden is International ADR monitoring centre $(50 \%)$, which indicates lack of awareness. Parthiban et al also reported lack of awareness about the International centre for ADR reporting (23\%) while only $17.4 \%$ of the students have the awareness regarding National Pharmacovigilance programmes. ${ }^{18}$ In this present study, $47 \%$ students know that Doctors, nurses and Pharmacist can report ADR as per the 
guidelines. Sound knowledge but poor awareness about ADR monitoring centers and reporting has also been observed among the undergraduate students and interns in various studies. ${ }^{18,19}$

In our study, only $45 \%$ participants think that ADR reporting is a professional obligation which is less as compared to other studies. ${ }^{12,20,21}$ This is the attitude component which needs to be modified for improving the underreporting of ADR. Good knowledge and attitude remove the misconceptions, obstacles and potential barriers to the activities that we would like to implement thus initiating the practices for reporting. In the present study, $88 \%$ people feel that ADR reporting may improve patient safety. $81 \%$ students have also seen ADR but surprisingly only $20 \%$ people have reported ADR. We can clearly see that practices for reporting are lacking which is also an observation by various other studies. ${ }^{21-23}$ Causes of underreporting are indifference to reporting, lack of interest in registration and lack of time for too many activities in the clinical routine. ${ }^{24}$ This underreporting can be overcome by making easy access to registration forms, simplifying documents, toll free number assistance, financial incentives, creating more ADR centre, facilitating communication between registrars and pharmacovigilance centers would improve the notification rates of problems related to medication. $^{25-27}$ Studies evaluating the attitudes of nursing staff found that the lack of knowledge in completing the notification form, and the lack of time to report ADRs are the main causes of underreporting in this class. $^{28,29}$ Therefore, strategies must be developed to improve the acquaintance of these professionals to the pharmacovigilance service. There is a need for training and educational activities like CMEs for increasing the awareness about reporting of ADRs. Importance on adverse event reporting should be emphasized while teaching undergraduate and post graduate students.

\section{CONCLUSION}

Poor reporting of ADR from countries including India is essentially due to absence of vibrant ADR monitoring system and also inadequacies in reporting culture among health care professionals. The reporting rate of ADR could be improved with proper and extensive training about Pharmacovigilance in health care professionals. We conclude that further large scale awareness of pharmacovigilance is required among medical students for better understanding of $\mathrm{ADR}$ and its reporting. Special emphasis of pharmacovigilance in medical curriculum and its incorporation in medical internship is required to bring more awareness about rational usage of drugs; thereby minimising the adverse drug events or other drug related problems.

Funding: No funding sources Conflict of interest: None declared

Ethical approval: The study was approved by the Institutional Ethics Committee

\section{REFERENCES}

1. The Importance of Pharmacovigilance; Safety monitoring of medicinal products. WHO information booklet: 2002. Available at http://apps.who.int/medicinedocs/en/d/Js4893e/

2. Handbook of resolutions and decisions of the World Health Assembly and Executive Board. 1972;11948. Geneva: World Health Organization, 1973. WHA16.36 Clinical and pharmacological Evaluation of Drugs.

3. Moore N. The role of the clinical pharmacologist in the management of ADRs. Drug Safety. 2001;24(1):1-7.

4. Bapna JS, Tripathi CD, Tekur U. Drug utilization patterns in the third world. Pharmacoeconomics. 1996;9(4):286-94.

5. Wysowski DK, Swartz L. Adverse drug event surveillance and drug withdrawals in the United States, 1969-2002: The importance of reporting suspected adverse drug reactions, Arch Intern Med. 2005;165:1363-9.

6. Ratan JL, Mangala L. An update on the Pharmacovigilance Programme of India. Front Pharmacol. 2015;6:194. Available at https://www.researchgate.net/publication/282513881

7. Drug Benefits and Risks - International Textbook of Clinical Pharmacology (2nd edition). Van Boxtel C, Santoso B and Edwards IR, eds. IOS Press, Amsterdam, 2008.

8. Vigibase LM. The WHO Global ICSR Database System: Basic Facts. Drug Information Journal. 2008;42:409-19.

9. Vallano A, Cereza G, Pedros C, Agusti A, Danes I, Aguilera C, et al. Obstacles and solutions for spontaneous reporting of adverse drug reactions in the hospital. Br J Clin Pharmacol. 2005;60(6):653-8.

10. Desai CK, Iyer PG, Panchal J, Shah S, Dikshit RK. An evaluation of knowledge, attitude, and practice of adverse drug reaction among prescriber at a tertiary care hospital. Perspect Clin Res. 2011;2(4):129-36.

11. Rajesh R, Vidyasagar S, Varma DM. An educational intervention to assess knowledge, Attitude, practice of spharmacovigilance among healthcare professional in an Indian tertiary care teaching hospital. Int J Pharm Tech Res. 2011;3(2):678-92.

12. Khan SA, Goyal C, Chandel N, Rafi M. Knowledge, attitudes, and practice of doctors to adverse drug reaction reporting in a teaching hospital in India: An observational study. J Nat Sci Biol Med. 2013;4(1):191-6.

13. Alan S, Ozturk M, Gokyildiz S, Avcibay B, Karatas $\mathrm{Y}$, An evaluation of knowledge of pharmacovigilance among nurses and midwives in Turkey. Indian $\mathbf{J}$ Pharmacol. 2013;45(6):616-8.

14. Fadare J, Enwere O, Afolabi AO, Chedi BAZ, Musa A. Knowledge, attitude and practice of adverse drug reaction reporting among healthcare workers in a tertiary centre in northern Nigeria. Trop J Pharm Res. 2011;10(3):235-42. 
15. Gupta P, Udupa A. Adverse drug reporting and pharmacovigilance: Knowledge, attitude and perception among resident doctors. J Pharm Sci Res. 2011;3:1064-6.

16. Palaian S, Ibrahim MI, Mishra P. Health professionals' knowledge, attitude and practices towards pharmacovigilance in Nepal. Pharm Pract (Granada) 2011;9:228-35.

17. Meher BR, Joshua N, Asha B, Mukherji D. A questionnaire based study to assess knowledge, attitude and practice of pharmacovigilance among undergraduate medical students in a Tertiary Care Teaching Hospital of South India. Perspect Clin Res. 2015;6:217-21.

18. Parthiban G, Nileshraj G, Mangaiarkkarasi A, Meher Ali R. A survey on knowledge, attitude and awareness of pharma covigilance among medical students in a teaching hospital, Puducherry. Indian Journal of Basic and Applied Medical Research. December 2015;5(1):198-203.

19. Hema NG, Bhuvana KB, Sangeetha. Pharmacovigilance: The extend of awareness among the final year students, interns and postgraduates in a government teaching hospital. J Clin Diagn Res. 2012;6(7):1248-53.

20. Datta S, Sengupta S. An evaluation of knowledge, attitude and practice of adverse drug reaction reporting in a tertiary care teaching hospital of Sikkim. Perspect Clin Res. 2015;6(4):200-6.

21. Ganesan S, Vikneswaran G, Reddy KC, Subrahmanyam DK, Adithan C. A Survey on Knowledge, Attitude and Practice of Pharmacovigilance towards Adverse drug reactions reporting among Doctors and Nurses in a Tertiary Care Hospital in South India. J Young Pharm. 2016;8(4):471-6.

22. Agarwal R, Daher AM, Ismail MN. Knowledge, practices and attitudes towards adverse drug reaction reporting by private practitioners from Klang valley in Malaysia. Malays J Med Sci. 2013;20(2):52-61.
23. Herdeiro MT, Figueiras A, Polónia J, Gestal-Otero J. Physicians' attitudes and adverse drug reaction reporting: a case-control study in Portugal. Drug Saf. 2005;28(9):825-33.

24. Avery AJ, Anderson C, Bond CM, Fortnum H, Gifford A, Hannaford PC, et al. Evaluation of patient reporting of adverse drug reactions to the UK 'Yellow Card Scheme': Literature review, descriptive and qualitative analyses, and questionnaire surveys. Health Technol Assess. 2011;15(20):1-234.

25. Kharkar M, Bowalekar S. Knowledge, attitude and perception/practices (KAP) of medical practitioners in India towards adverse drug reaction (ADR) reporting. Perspect Clin Res. 2012 Jul-Sep;3;3:90-4.

26. Nichols V, Thériault-Dubé I, Touzin J, Delisle JF, Lebel D, Bussières JF, et al. Risk perception and reasons for noncompliance in pharmacovigilance: a qualitative study conducted in Canadá. Drug Saf. 2009;32(7):579-90.

27. Gavaza P, Brown CM, Khoza S. Texas pharmacists' opinions on reporting serious adverse drug events to the Food and Drug Administration: a qualitative study. Pharm World Sci. 2010;32(5):651-7.

28. Li Q, Zhang SM, Chen HT, Fang SP, Yu X, Liu D, et al. Awareness and attitudes of healthcare professionals in Wuhan, China to the reporting of adverse drug reactions. Chin Med J. 2004;117(6):856-61.

29. Pernas SIS, Herdeiro MT, Lopez-Gonzalez E, da Cruz e Silva OA, Figueiras A. Attitudes of Portuguese health professionals toward adverse drug reaction reporting. Int $\mathbf{J}$ Clin Pharm. 2012;34(5):693-8.

Cite this article as: Dhananjay $\mathrm{K}$, Esanakula $\mathrm{H}$. A study of assessing knowledge, attitude and practice of pharmacovigilance among medical students of a South Indian teaching hospital. Int J Basic Clin Pharmacol 2017;6:43-7. 